\title{
Physicochemical and Rheological Properties of a Transparent Asphalt Binder Modified with Nano- $\mathrm{TiO}_{2}$
}

\author{
Iran Rocha Segundo ${ }^{1, *}{ }^{-}$, Salmon Landi, Jr. ${ }^{2}{ }^{-}$, Alexandros Margaritis ${ }^{3}{ }^{(0)}$,

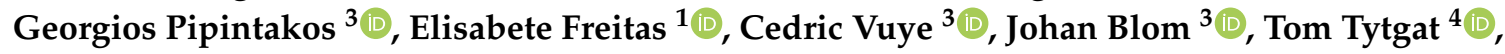 \\ Siegfried Denys ${ }^{4}$ and Joaquim Carneiro ${ }^{5}$ (i) \\ 1 Department of Civil Engineering, University of Minho, 4800-058 Guimarães, Portugal; \\ efreitas@civil.uminho.pt \\ 2 Federal Institute Goiano, Rio Verde 75901-970, Brazil; salmon.landi@ifgoiano.edu.br \\ 3 Energy and Materials in Infrastructure and Buildings (EMIB) Research Group, University of Antwerp, \\ 2020 Antwerp, Belgium; alexandros.margaritis@uantwerpen.be (A.M.); \\ georgios.pipintakos@uantwerpen.be (G.P.); cedric.vuye@uantwerpen.be (C.V.); \\ johan.blom@uantwerpen.be (J.B.) \\ 4 Research Group Sustainable Energy, Air and Water Technology, University of Antwerp, \\ 2020 Antwerp, Belgium; tom.tytgat@uantwerpen.be (T.T.); siegfried.denys@uantwerpen.be (S.D.) \\ 5 Centre of Physics, University of Minho, 4800-058 Guimarães, Portugal; carneiro@fisica.uminho.pt \\ * Correspondence: iran_gomes@hotmail.com
}

Received: 16 September 2020; Accepted: 23 October 2020; Published: 28 October 2020

\begin{abstract}
Transparent binder is used to substitute conventional black asphalt binder and to provide light-colored pavements, whereas nano- $\mathrm{TiO}_{2}$ has the potential to promote photocatalytic and self-cleaning properties. Together, these materials provide multifunction effects and benefits when the pavement is submitted to high solar irradiation. This paper analyzes the physicochemical and rheological properties of a transparent binder modified with $0.5 \%, 3.0 \%, 6.0 \%$, and $10.0 \%$ nano- $-\mathrm{TiO}_{2}$ and compares it to the transparent base binder and conventional and polymer modified binders (PMB) without nano-TiO ${ }_{2}$. Their penetration, softening point, dynamic viscosity, master curve, black diagram, Linear Amplitude Sweep (LAS), Multiple Stress Creep Recovery (MSCR), and Fourier Transform Infrared Spectroscopy (FTIR) were obtained. The transparent binders (base and modified) seem to be workable considering their viscosity, and exhibited values between the conventional binder and PMB with respect to rutting resistance, penetration, and softening point. They showed similar behavior to the PMB, demonstrating signs of polymer modification. The addition $\mathrm{of}^{\mathrm{TiO}_{2}}$ seemed to reduce fatigue life, except for the $0.5 \%$ content. Nevertheless, its addition in high contents increased the rutting resistance. The $\mathrm{TiO}_{2}$ modification seems to have little effect on the chemical functional indices. The best percentage of $\mathrm{TiO}_{2}$ was $0.5 \%$, with respect to fatigue, and $10.0 \%$ with respect to permanent deformation.
\end{abstract}

Keywords: asphalt binder; transparent binder; nanomaterials; $\mathrm{TiO}_{2}$; viscoelastic properties; FTIR; photocatalytic asphalt; light-colored asphalt; self-cleaning

\section{Introduction}

For specific applications, it is important to control the light absorption and thermal energy storage in asphalt pavements, which can be carried out by the application of light-colored pavements [1]. Light and heat are essential influencing factors for asphalt pavements. Firstly, it is well known that they are essential keys for the asphalt binder aging, causing damage to asphalt roads [2,3]. The absence of light profoundly affects the visibility conditions, decreasing safety [1]. In contrast, a large amount of 
heating can increase the Urban Heat Island (UHI) effect in urban areas [4]. The conventional black color of asphalt pavements absorbs light and stores a large amount of thermal energy.

According to the World Health Organization (WHO), more than $90 \%$ of the global population lives in places where the concentrations of pollutants exceed their limits, presenting, as consequences, intensification of the greenhouse effect, acid rain, and public health problems, for example. The indispensable urgency for the reduction of air pollutants is clear from different scales and needs. As such, the introduction of semiconductor nanoparticles into asphalt mixtures can make part of the solutions available to mitigate air-quality problems [5-11].

It is estimated that $40 \%$ of urban areas are covered by pavements due to the rapid human development, affecting the local ecosystems and the subjacent surface conditions. Nowadays, another urban problem is the UHI phenomenon, which is the increase of temperatures in cities in comparison to the colder conditions of suburban zones and rural areas, due to the massive development of urbanization [4,12]. Traditional (asphalt) pavements and roofs absorb and store most of the solar energy during the day, which is released in the form of heat during the night. The dark surfaces of, for example, asphalt pavements are characterized by a sunlight reflection up to only $20 \%$. Therefore, light-colored road pavements can be considered a viable technology to tackle this phenomenon. Additionally, these surfaces reduce the heat convection from pavement to air with a consequent decrease of ambient air temperature. Its high reflectivity reduces the overheating during the summer period, resulting in less distress and increased pavement durability [1,3].

A common practice for separating asphalt binder fractions is to fractionate it based on polarity using different solvents. By this method, the following fractions are obtained: asphaltenes, resins, aromatics, and saturates with decreasing polarity order [13]. To obtain light-colored asphalt pavements, transparent binders can be used. Thus, they are produced through three different processes: (i) bitumen modification based on the extraction of asphaltenes that are responsible for the black color of bitumen; (ii) synthetic binder production by transparent polymer materials; and (iii) blending specific resins with bio-oils or organic vegetal origin materials [1,3]. Even though they are not bituminous materials, their rheological properties are similar to asphalt bitumens [1]. They can even contribute to electricity cost savings (and reduced pollutant emissions) due to the increased visibility in dark areas, for example, in tunnels, and, consequently, a reduced need for lighting [1].

Hitherto, little research has been focused on the physicochemical and rheological properties of light-colored binders. Additionally, the use of $\mathrm{TiO}_{2}$ can bring two benefits in this sense besides environmental effects: (i) the functionalization by providing photocatalytic capability can contribute to the environmental remediation; and (ii) development of lighter asphalt mixture, e.g., from dark brown to light yellow, depending on the used granulates, which can mitigate the UHI.

The literature presents a small number of studies addressing the use of the transparent binder. For example, Bocci et al. (2012) produced a light-colored asphalt mixture with conventional aggregates, lime filler, light-colored binder, and $\mathrm{TiO}_{2}$ powder ( $1 \%$ by aggregate weight). The coefficient of reflection related to night visibility and the luminance of this technology were much higher than those from the conventional asphalt mixture [1]. Bocci E. and Bocci M. (2014) continued their research on this subject, showing that light-colored dense-graded mixtures have similar mechanical properties when compared to the conventional asphalt mixture. They concluded that the light-colored asphalt pavement presented very high photometric properties even after five months from the traffic opening [14]. Sengoz et al. (2017) investigated the rheological properties of transparent binder in comparison to a traditional black bitumen. They concluded that the transparent and the traditional black bitumen had a similar performance [3]. 
On the basis of a review of the previous literature, there is a gap considering the rheological behavior of transparent binders modified with nano- $\mathrm{TiO}_{2}$. The use of these two materials together would combine their benefits into one single product: an asphalt pavement capable to photodegrade pollutants and avoid the UHI. The main objective of this research is to analyze the physicochemical and rheological properties of a transparent binder modified with nano- $\mathrm{TiO}_{2}(0.5 \%, 3.0 \%, 6.0 \%$, and $10.0 \%)$ for the understanding of its limitations and definition of suitable destinations. For this, its physical (conventional), rheological, and chemical properties were assessed and compared to those of a conventional asphalt binder and a commercial PMB.

\section{Materials}

\subsection{Binders}

In this research, the transparent binder Kromatis 50/70 from Total (Rives-en-Seine, France) was used. According to the supplier, this light-colored synthetic binder presents properties similar to other bitumens. It is produced with hydrocarbon resins and low content of asphaltenes, which are removed and replaced with new elastomeric polymers [15].

A conventional 50/70 bitumen and a polymer-modified binder (PMB) (SBS-modified bitumen) were also used in this study. These reference binders were named as N50/70 and PMBTS, respectively.

\section{2. $\mathrm{TiO}_{2}$ Nanoparticles}

The semiconductor selected to provide multifunctional properties was the nano- $\mathrm{TiO}_{2}$ by Quimidroga (Aeroxide $\mathrm{TiO}_{2}$ P25) (Barcelona, Spain). Its main properties are $80 \%$ anatase and $20 \%$ rutile crystalline phases, purity $>99.5 \%$, and particle size about 23 to $28 \mathrm{~nm}$.

\subsection{Sample Preparation}

The nanoparticles were incorporated into the binder (at $150{ }^{\circ} \mathrm{C}$ for $30 \mathrm{~min}$ in a low shear mixer with a rotational speed of 1500 RPM) with four different contents: $0.5,3.0,6.0$ and $10.0 \%$ (in the mass of the binder) with a similar modification procedure adopted in the literature review [10,16-18]. The particles were placed when the low shear mixer was working, homogenizing the binder already heated to $150{ }^{\circ} \mathrm{C}$. All safety precautions were taken, considering personal protective equipment, engineering control (ventilated enclosures), and hygiene, among other things.

The samples were named by the modification content: $0.5 \%, 3.0 \%, 6.0 \%$ and $10.0 \%$. With the introduction of nano- $\mathrm{TiO}_{2}$, the color of the binder changes from dark brown ( $\left.0 \%\right)$ to light yellow $(10.0 \%)$, see Figure 1. One blend was prepared for each content. Regarding the performed tests, the number of replicates respected the requirements mentioned in the relevant European standard. 


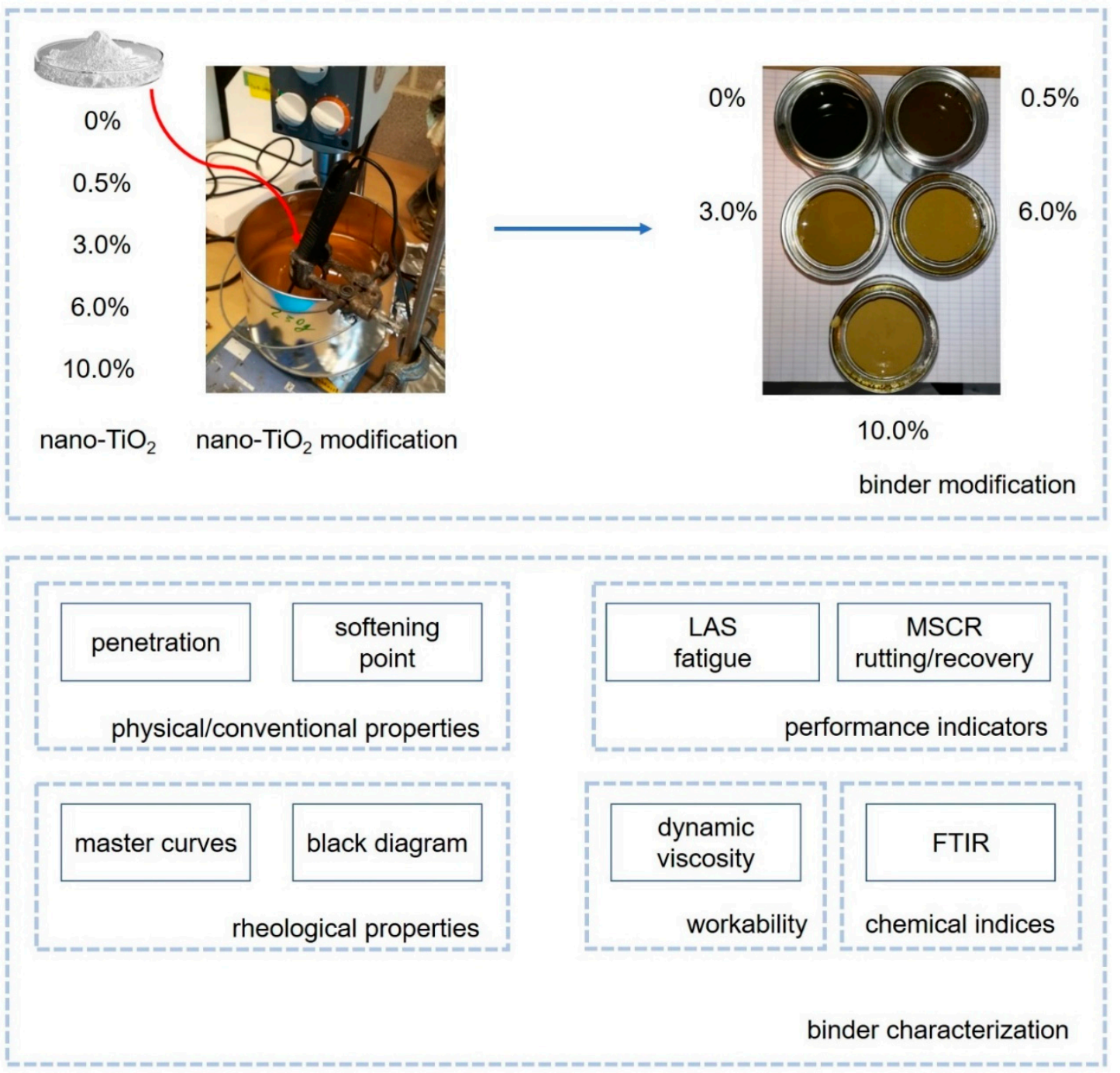

Figure 1. Schematic representation of this research.

\section{Methods}

Different tests were carried out, such as penetration, softening point, Dynamic Shear Rheometer (DSR) tests (complex modulus, Linear Amplitude Sweep-LAS, Multiple Stress Creep Recovery-MSCR), Dynamic viscosity and Fourier Transform Infrared (FTIR) spectroscopy, in order to determine conventional, rheological and chemical properties. Figure 1 presents the schematic summary of the preparation and characterization methodology adopted in this paper.

\subsection{Penetration and Softening Point}

Penetration and softening point were tested according to EN 1426/2015 and EN 1427/2015, respectively. They indicate the basic properties of asphalt binders.

\subsection{Dynamic Viscosity}

A dynamic viscosity test was carried out following the EN 13302/2010 standard, but only for the transparent binders (with and without nano- $\mathrm{TiO}_{2}$ ). The objective was to evaluate the workability of the binders according to Superpave specifications. The highest allowed viscosity to respect the workability is $3 \times 10^{3} \mathrm{cP}$ (or $\left.3 \mathrm{~Pa} \cdot \mathrm{s}\right)$ at $135^{\circ} \mathrm{C}[19,20]$. 


\subsection{Viscoelastic Behavior}

The viscoelastic behavior of the binders was assessed using the Dynamic Shear Rheometer (DSR). The DSR used in this study is an Anton Paar MCR 500 (Graz, Austria). For temperature ranges from $0{ }^{\circ} \mathrm{C}$ to $+40^{\circ} \mathrm{C}$ and from $+40^{\circ} \mathrm{C}$ to $+80^{\circ} \mathrm{C}$, the $8 \mathrm{~mm}$ and $25 \mathrm{~mm}$ plate geometries were used, accordingly, as described in EN 14770:2012. For each temperature step (increments of $10^{\circ} \mathrm{C}$ ), frequency sweep tests were performed $(0.1-10 \mathrm{~Hz})$ on two replicates per binder sample, within the linear viscoelastic region (LVER) of the binders. The data were further analyzed using the RHEA ${ }^{\mathrm{TM}}$ software (v2.0, Abatech, Blooming Glen, PA, USA) [21]. The shifting of the data was performed using the Gordon and Shaw procedure [22]. The phase angle and complex modulus master curves are presented in their original format, without fitting any mathematical or mechanical models.

Black diagrams (complex modulus versus phase angle) aim to identify discrepancies of the rheological data, breakdown of time-temperature equivalence, and thermo-rheological simplicity [23]. A smooth curve indicates time-temperature equivalence, a typical response of unmodified binders. On the other hand, discontinuities indicate the presence of high wax content bitumen, highly polymer modified bitumen, or a highly asphaltene structured binder [23]. Additionally, it is possible to notice whether there are different dominances when the binder is a composite [23]. This phenomenon happens, for example, when the complex modulus trend changes with the increase of the phase angle, a phenomenon known as curling.

\subsection{Fatigue Resistance (LAS Test)}

To evaluate the fatigue resistance of bituminous binders, the Linear Amplitude Sweep (LAS) test was performed. This test is an accelerated method that uses the DSR ( $8 \mathrm{~mm}$ parallel plate geometry at $15^{\circ} \mathrm{C}$ ), which consists of two steps: (i) firstly, a frequency sweep test, and (ii) secondly, an amplitude sweep test, as described in AASHTO TP 101-14. The frequency sweep test $(0.2-30 \mathrm{~Hz})$ is used to define the undamaged properties and fatigue law parameters, at a strain level of $0.1 \%$. A linear amplitude sweep test is performed at $10 \mathrm{~Hz}$, and the strain amplitude is linearly increased over 3000 cycles, from 1\% to 30\%. The Viscoelastic Continuum Damage (VECD) theory is used to determine the parameters $A$ and $B$ of the fatigue law (Equation (1)) [24], in order to determine the fatigue life (Nf). The failure point is determined as the point when the product of the complex modulus $\left(G^{*}\right)$ and phase angle $(\delta)$ sine is reduced by $35 \%$ from its initial value.

$$
N f=A \gamma^{B}
$$

Both the fatigue curves and the Nf for strain levels $(\gamma)$ equal to $2.5 \%$ and $5 \%$, related to a strong and weak pavement [25], respectively, will be presented.

\subsection{Rutting Resistance Indicator (MSCR Test)}

The Multiple Stress Creep Recovery (MSCR) was performed using the DSR together with the $25 \mathrm{~mm}$ plate and $1 \mathrm{~mm}$ gap, as described in EN 16659:2015. The test was performed at $50{ }^{\circ} \mathrm{C}$, at two different stress levels ( 0.1 and $3.2 \mathrm{kPa})$ over ten load cycles. Each cycle consists of $1 \mathrm{~s}$ loading followed by $9 \mathrm{~s}$ of a recovery period, from which two parameters are obtained: (i) the non-recoverable creep compliance $\operatorname{Jnr}\left(\mathrm{Pa}^{-1}\right)$, which is the ratio between the residual strain and the stress applied; and (ii) the recovery $R(\%)$, showing proportionally how much strain the sample recovers at the end of the cycle. $R(\%)$ can be used to identify the presence of polymer modifications in the asphalt binders.

\subsection{FTIR}

Chemical characterization of binders has received attention in the literature as it can present functional groups related to the crude oil origin, the polymer modification, and the degree of oxidation [26-31]. Since this paper aims to analyze the chemical characteristics of the transparent binder modified with nano- $\mathrm{TiO}_{2}$, three approaches were carried out: (i) identification of FTIR peaks; 
(ii) establishment of a possible relationship between the $\mathrm{TiO}_{2}$ modification level and related chemical groups; and (iii) comparison of standard indices with reference binders used in this study.

The Thermo Scientific Nicolet iS10 Fourier Transform Infrared (FTIR) spectrometer (Waltham, MA, USA) is equipped with an Attenuated Total Reflectance (ATR) fixture and a Smart Orbit Sampling Accessory. The average spectra were obtained after the acquisition of the spectra, 32 repetitive scans in the range $400 \mathrm{~cm}^{-1}$ to $4000 \mathrm{~cm}^{-1}$ with a resolution of $4 \mathrm{~cm}^{-1}$ were performed to deliver an average spectrum. A hot droplet of each binder was placed on the crystal, and its respective spectrum was measured.

The chemical structure of the binders was analyzed using indices, $I$, from the obtained FTIR spectrum [32]. Each I (Equation (2)) is calculated by the ratio of the peak area of the identified band by the total area (Equation (3)) of the spectrum.

$$
\begin{gathered}
I_{\text {Functional Group }}=\frac{A_{i}}{\Sigma A} \\
\Sigma \mathrm{A}=\mathrm{A}_{1700}+\mathrm{A}_{1600}+\mathrm{A}_{1460}+\mathrm{A}_{1376}+\mathrm{A}_{1030}+\mathrm{A}_{864}+\mathrm{A}_{818}+\mathrm{A}_{743}+\mathrm{A}_{724} \\
+\mathrm{A}_{(2953,2923,2862)}
\end{gathered}
$$

where $A_{i}$ is the peak area of the specific functional group.

The areas defined by the introduced baselines and the part of the spectrum were calculated using a specific software Origin. Each peak is attributed to a functional group remaining unaffected during service life, but also to groups responsible for aging or polymer presence [26,28]. When it comes to the groups responsible for $\mathrm{TiO}_{2}$, echoing [33-35] in the region below $1000 \mathrm{~cm}^{-1}$, several peaks are ascribed to $\mathrm{TiO}_{2}$ presence. Previous researchers have demonstrated that the peak around $657 \mathrm{~cm}^{-1}$ is attributed to Ti-O-Ti stretching vibration, whereas the peak around $590 \mathrm{~cm}^{-1}$ is due to the vibration of Ti-O-O. A broader band of wavenumbers was calculated around these peaks in order to capture their increase by elevating the $\mathrm{TiO}_{2}$ modification level. It should be noted that a horizontal baseline coinciding with the $X$-axis was used for the calculation of this area. RI (Equation (4)) was calculated in order to check

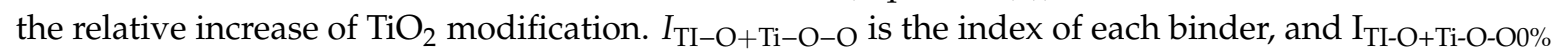
is the index of the transparent base binder $(0 \%)$.

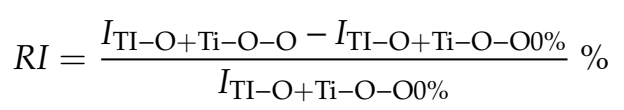

More specifically, for asphalt binders, the sulfoxide, carbonyl, aromatic, aliphatic, branched aliphatic, long chains, polybutadiene, and polystyrene indices were calculated. Sulfoxide and carbonyl indices are both related to aging.

They were calculated considering the following method: (i) aromatic index: $\mathrm{A}_{1600} / \Sigma \mathrm{A}$; (ii) aliphatic index: $\left(\mathrm{A}_{1460}+\mathrm{A}_{1376}\right) / \Sigma \mathrm{A}$; (iii) branched index: $\mathrm{A}_{1360} /\left(\mathrm{A}_{1460}+\mathrm{A}_{1376}\right)$; (iv) long chain index: $\mathrm{A}_{724} /\left(\mathrm{A}_{1460}+\mathrm{A}_{1376}\right) ;(\mathrm{v})$ carbonyl index: $\mathrm{A}_{1700} / \Sigma \mathrm{A} ;(\mathrm{vi})$ sulphoxide index: $\mathrm{A}_{1030} / \Sigma \mathrm{A}$; (vii) polybutadiene index: $\mathrm{A}_{966} / \Sigma \mathrm{A}$; and (viii) polystyrene index: $\mathrm{A}_{699} / \Sigma \mathrm{A}$.

Aromatic, aliphatic, branched aliphatic, and long chains are the structural groups of asphalt binders. Polybutadiene and polystyrene are associated with SBS modified binders. For details concerning the determination of standard indices related to oxidative aging of the binder, the reader is referred to the protocol described in [32]. Briefly, a common practice in this processing method is to introduce tangential baselines defined by limits around certain peaks [36].

\section{Results and Discussion}

\subsection{Penetration and Softening Point}

Figures 2 and 3 show the resulting penetration and softening point of the studied binders. When compared to the transparent base binder, the inclusion of $0.5 \%, 3.0 \%$ and $6.0 \% \mathrm{TiO}_{2}$ 
nano-modification decreased the penetration from 49 to 47,45 , and $47 \times 10^{-1} \mathrm{~mm}$, respectively. For $10.0 \% \mathrm{TiO}_{2}$, it increased to $53 \times 10^{-1} \mathrm{~mm}$, which is similar to the N50/70 results. When compared to the PMBTS, all the penetration results were higher. Therefore, the penetration values of the Kromatis binder were between the conventional and the PMB binders.

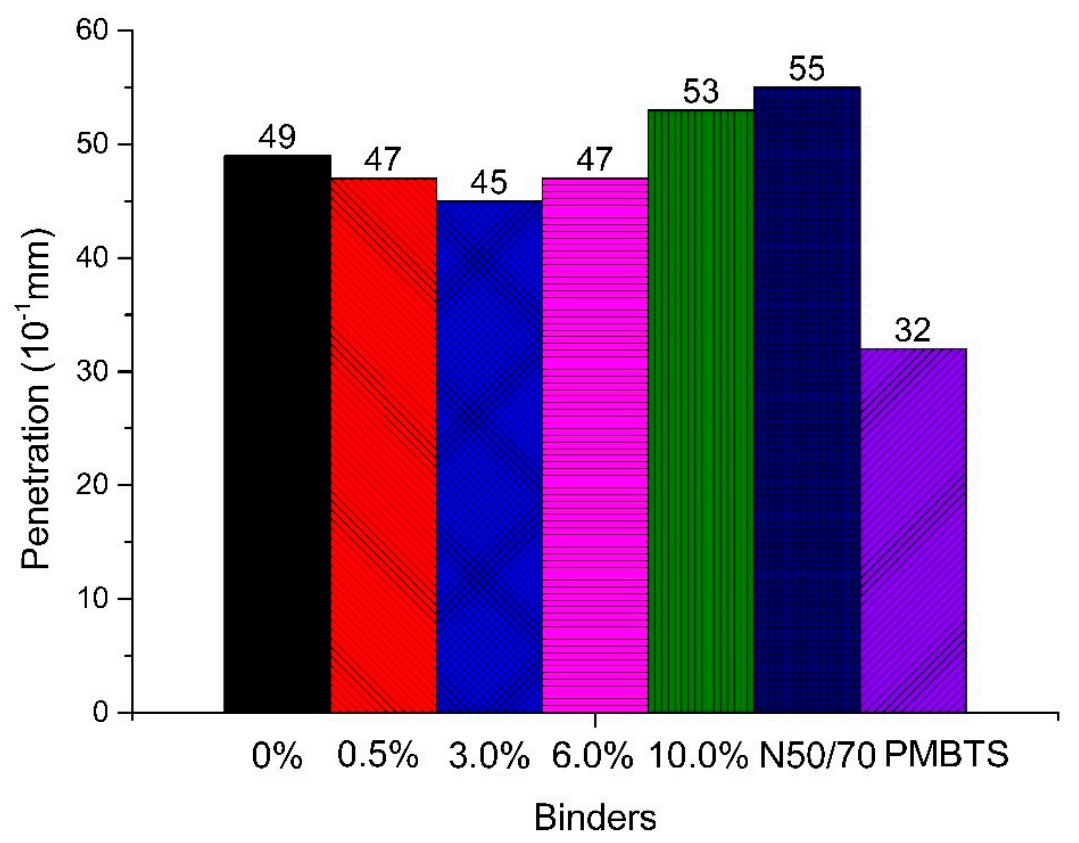

Figure 2. Penetration results of the binders of this study.

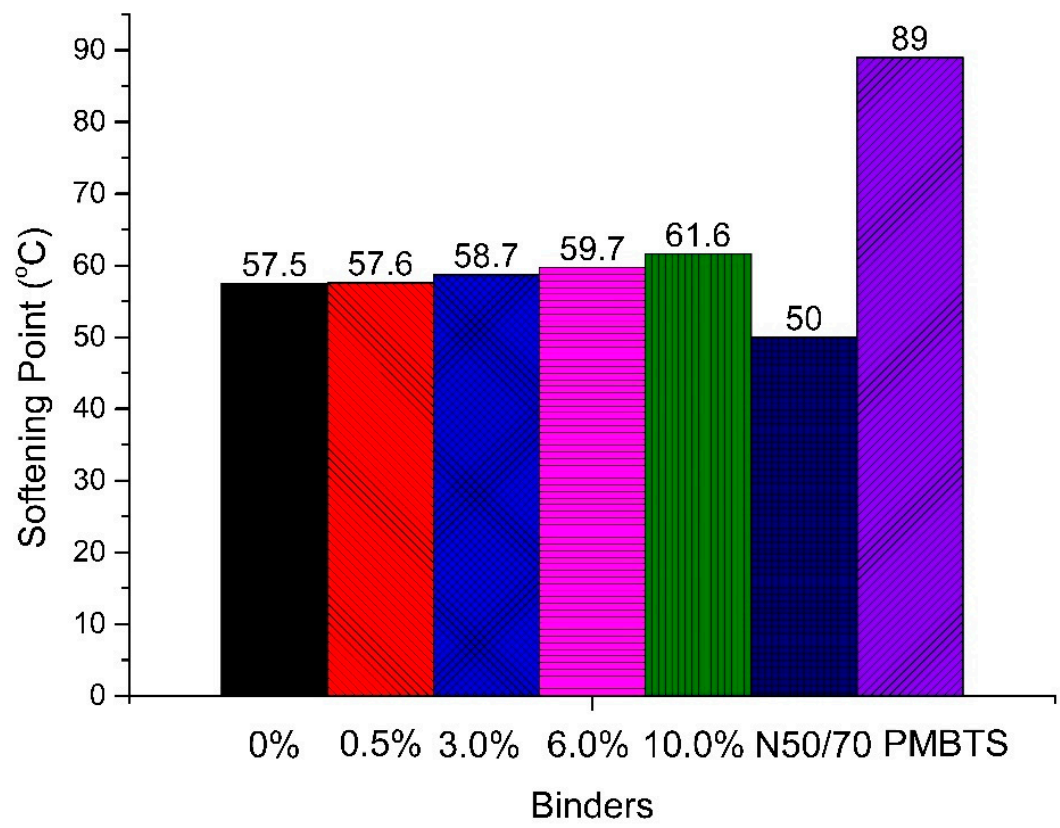

Figure 3. Softening point results of the binders of this study.

For the softening point, the results of the transparent binders were around $59{ }^{\circ} \mathrm{C}$. The increase of the $\mathrm{TiO}_{2}$ content gradually increased the softening point by about $4{ }^{\circ} \mathrm{C}$. The transparent binders had a softening point again between those of the conventional and the PMB binders.

Comparing these results to those obtained by Sengoz et al. (2017) for the same binder from the same supplier, they showed that the penetration and softening points were $55 \times 10^{-1} \mathrm{~mm}$ and $56{ }^{\circ} \mathrm{C}$ [3]. Thus, in this research, the transparent base binder had a lower penetration but a higher softening point [3]. 
It can be concluded that the transparent binders had results between those of the conventional and the PMB binders, but closer to those of the conventional one. The incorporation of nano- $\mathrm{TiO}_{2}$ gradually increased the softening point. For the penetration, the results were lower until $6.0 \%$, but higher for $10.0 \%$.

\subsection{Dynamic Viscosity}

The dynamic viscosity, determined only for the transparent binders, is shown in Figure 4. The introduction of nano- $\mathrm{TiO}_{2}$ increased dynamic viscosity. At $135^{\circ} \mathrm{C}$, the viscosity increased from $1 \times 10^{3} \mathrm{cP}$ (for the base binder) to $2.3 \times 10^{3} \mathrm{cP}$ (for the $10.0 \%$ ). Additionally, all the binders had a viscosity lower than $3 \times 10^{3} \mathrm{cP}$, considered as the recommended maximum viscosity criterion under Superpave to guarantee proper binder pumping in the asphalt plant during production [37]. If this value is higher than $3 \times 10^{3} \mathrm{cP}$, excessive energy is needed for the mixing and compaction of asphalt mixtures [19]. It can be concluded that all the modified transparent binders using the contents of nano- $\mathrm{TiO}_{2}$ studied (from 0 to $10.0 \%$ ) are feasible with respect to their workability. It is also interesting that the $10.0 \% \mathrm{TiO}_{2}$ appears to have the highest energy requirements as its viscosity is close to the Superpave threshold. Thus, from an economic point of view, it would be favorable to target lower $\mathrm{TiO}_{2}$ levels.

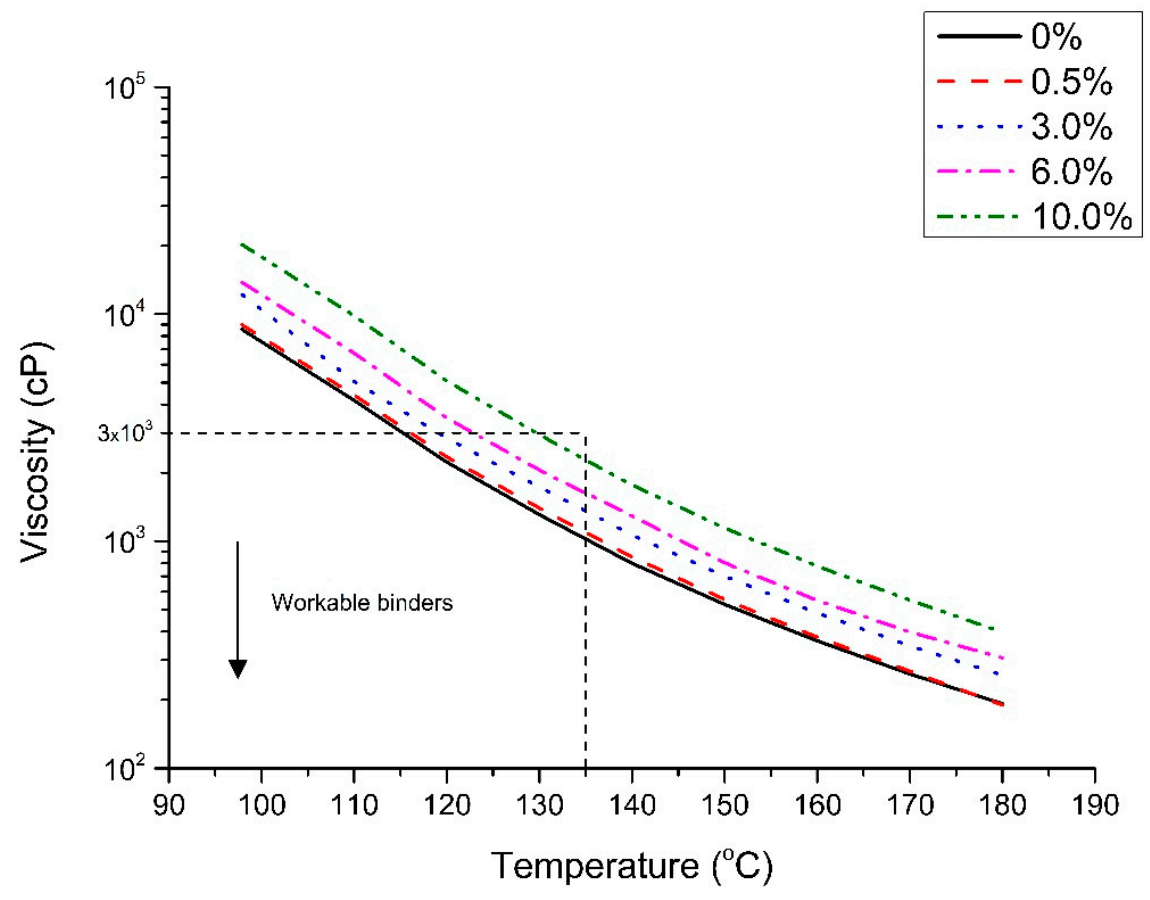

Figure 4. Dynamic viscosity results of the binders of this study.

In addition, the comparison of the results to those from the literature reveals that a higher viscosity was reached $\left(1 \times 10^{3} \mathrm{cP}\right)$. For example, Sengoz et al. (2017) presented $788 \mathrm{cP}$ in dynamic viscosity for the same transparent binder [3].

\subsection{Viscoelastic Behavior}

The complex modulus and phase angle master curves are presented in Figure $5 \mathrm{a}, \mathrm{b}$. The addition of $\mathrm{TiO}_{2}$ slightly alters the viscoelastic behavior of the transparent binder, leading to a simultaneous small increase of modulus and a decrease of the phase angle. The N50/70 shows a simple viscoelastic behavior with the phase angle gradually approaching the viscous asymptote of $90^{\circ}$ at elevated temperatures, a typical response of an unmodified binder. Concerning the complex modulus, the N50/70 shows similar values to the PMBTS at frequencies above $10 \mathrm{~Hz}$. At low frequencies (related to high temperature), 
N50/70 shows the lowest complex modulus compared to other binders, which was an expected observation, since the modulus of those binders is greatly influenced by the polymer modification.
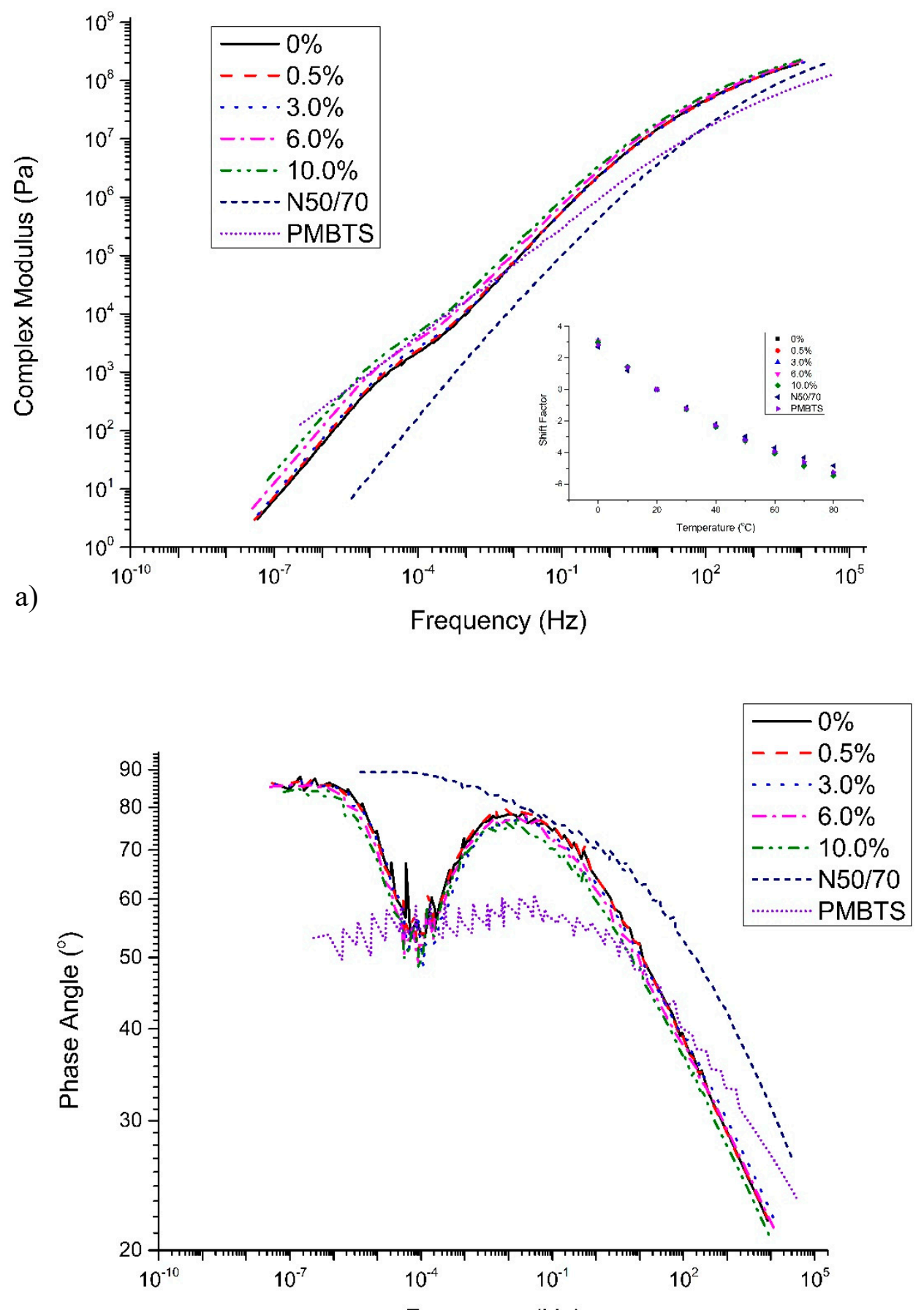

b)

Frequency $(\mathrm{Hz})$

Figure 5. (a) Complex modulus and (b) phase angle master curves of the binders of this study.

Comparing the transparent binder with the PMBTS, it can be seen that the complex modulus is similar at lower frequencies, while the PMBTS demonstrates a lower modulus at frequencies above $0.01 \mathrm{~Hz}$. Looking at the phase angle, both reveal the presence of elastomeric modification, which is visible by the drop of the phase angle at a low reduced frequency. For the PMBTS, the dominance of the polymeric phase starts below $1 \mathrm{~Hz}$ and shows at a steady plateau stage of $60^{\circ}$. On the other hand, the dominance of the polymeric phase for the transparent binders starts after $0.01 \mathrm{~Hz}$ (which can 
be translated that the polymer network is "active" at higher temperatures compared to the PMBTS), showing a significant drop of the phase angle and then gradually approaching the viscous asymptote of $90^{\circ}$.

The last part shows that the polymer network is no longer dominant. Those distinct differences can be attributed to the difference between the base binders as well as the compatibility between base and polymer [38]. Another possibility is the thermal history of the binders, which can significantly influence the rheological behavior of elastomeric binders, as demonstrated by Soenen et al. [39].

The black diagram (Figure 6) shows the combined effect of complex modulus and phase angle for the different binders. The N50/70 binder presents a conventional black diagram curve. Therefore, it is smooth, and the complex modulus decreases while the phase angle increases. The presence of a polymer can be seen by the shift of the curve towards a lower phase angle (higher elastic behavior) [23]. More specifically, for the PMBTS, the plateau near $60^{\circ}$ (at a temperature of $58^{\circ} \mathrm{C}$ ) can indicate that the polymer forms a continuous elastic network when dissolved in bitumen, making it a polymer-dominant phase.

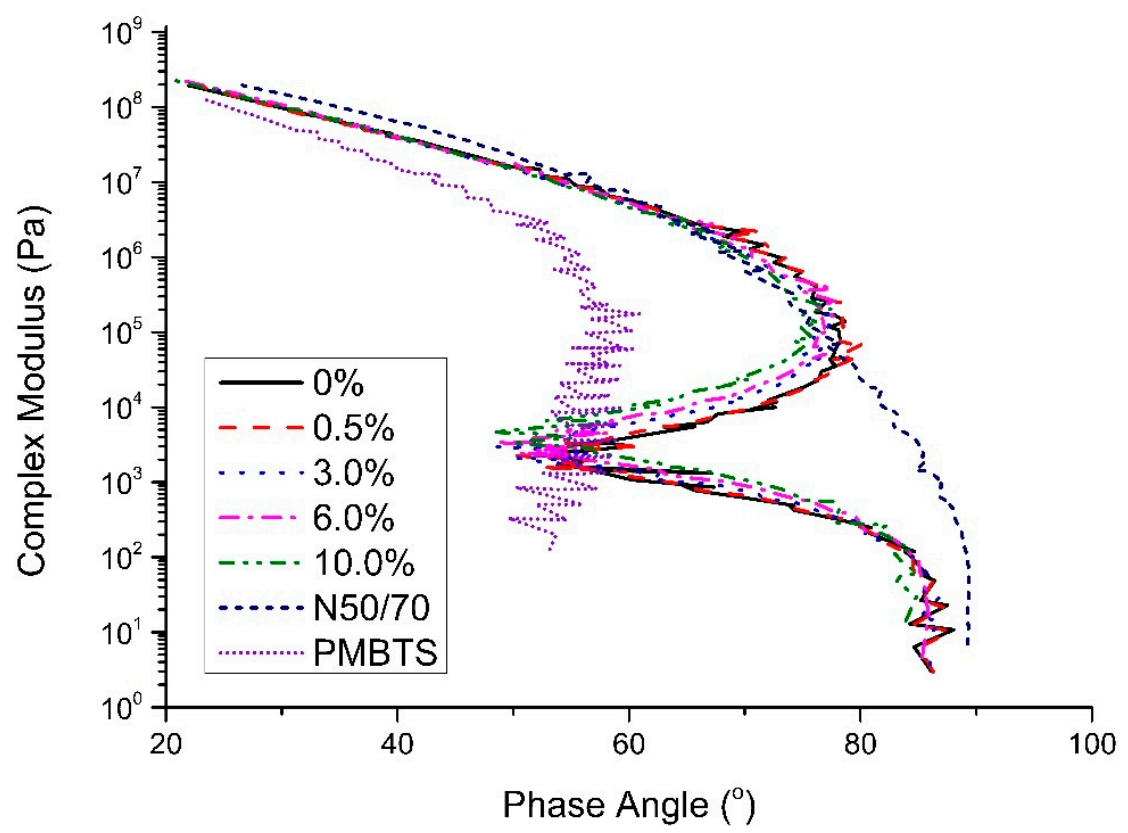

Figure 6. Black diagram of the evaluated reference and transparent binders.

The shape of the curve of the transparent binders is different from the reference ones, showing three distinctive regions: (i) from $10^{8}$ to $5 \times 10^{5} \mathrm{~Pa}$, the complex modulus decreases with the increase of the phase angle; (ii) from $5 \times 10^{5}$ to $5 \times 10^{4} \mathrm{~Pa}$, the complex modulus decreases when the phase angle increases; and (iii) from $5 \times 10^{4} \mathrm{~Pa}$, with the same pattern to that of the first region, including the shape. This viscoelastic response indicates an alternation of dominance between the materials that compose the transparent binders, as also observed in the phase angle master curve. Additionally, transparent binders seem to be more elastic than N50/70, with a partial shift towards the left. The addition of $\mathrm{TiO}_{2}$ seems to have a small, rather insignificant, effect on the viscoelasticity of the transparent binder. Based on the observations of the master curves and black diagram, the addition of $\mathrm{TiO}_{2}$ up to $10.0 \%$ seems not to introduce any noticeable effect on the structure of the transparent binders.

\subsection{Fatigue Resistance (LAS Test)}

The fatigue curves of each binder are presented in Figure 7 and the corresponding parameters are further elaborated in Table 1. 


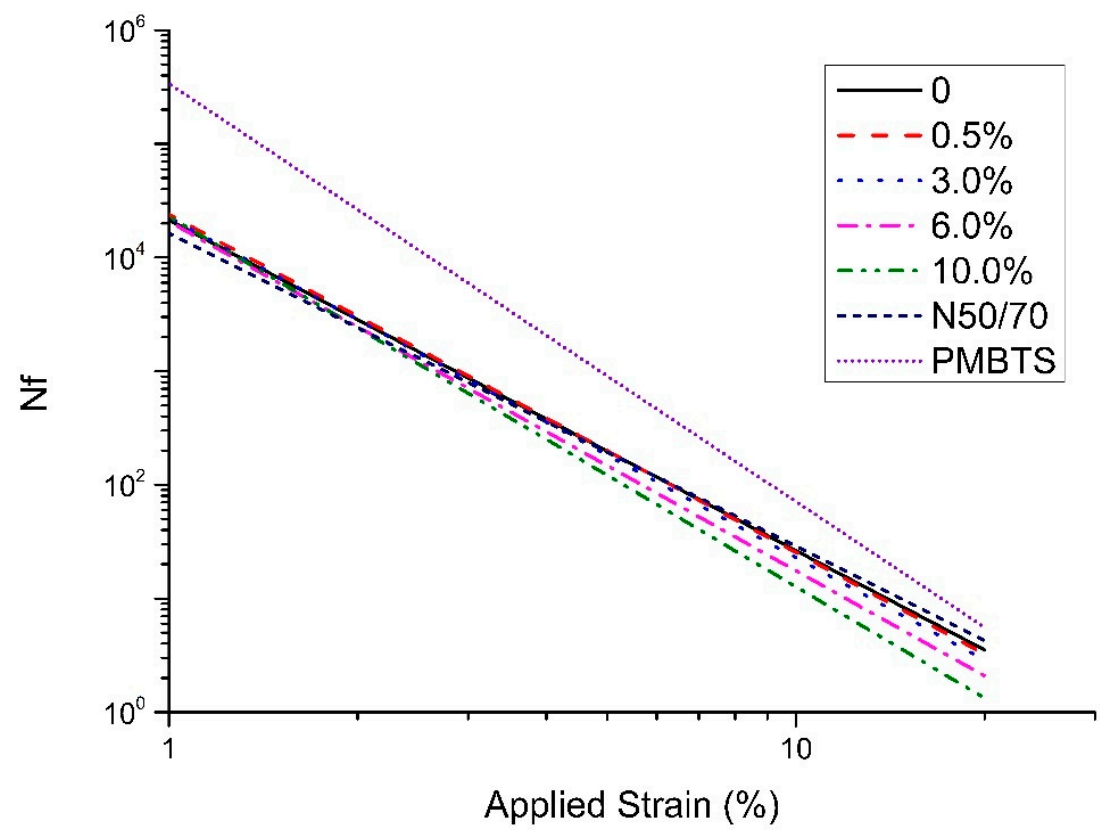

Figure 7. LAS Test: Nf versus applied strain.

Table 1. LAS test results.

\begin{tabular}{ccccc}
\hline \multirow{2}{*}{ Binder } & \multicolumn{4}{c}{ Parameter } \\
\cline { 2 - 5 } & $\mathbf{A}$ & $\mathbf{B}$ & $\mathrm{Nf} \mathbf{2 . 5 \%}$ & $\mathrm{Nf} \mathbf{5 \%}$ \\
\hline $0 \%$ & 21,348 & -2.9 & 1486 & 198 \\
$0.5 \%$ & 23,946 & -3.0 & 1568 & 199 \\
$3.0 \%$ & 22,578 & -3.0 & 1453 & 182 \\
$6.0 \%$ & 20,724 & -3.1 & 1241 & 148 \\
$10.0 \%$ & 22,942 & -3.3 & 1160 & 121 \\
N50/70 & 16,303 & -2.8 & 1308 & 194 \\
PMBTS & 338,013 & -3.7 & 11,631 & 909 \\
\hline
\end{tabular}

The PMBTS shows the highest fatigue resistance among the binder samples, while the transparent base binder and the N50/70 showed similar results. The addition of $\mathrm{TiO}_{2}$ seems to harm the fatigue life of the transparent binder, except for the $0.5 \%$ dosage, where it shows a slightly improved fatigue life. In more detail, the addition of $\mathrm{TiO}_{2}$ leads to a proportional decrease of the slope (parameter $\mathrm{B}$ ), while no clear trend is evident on the effect of $\mathrm{TiO}_{2}$ on the intercept (parameter $\mathrm{A}$ ).

For all the binders, from the lowest to the highest fatigue performance considering the applied strain of 2.5\% (representative strain level of a "weak" pavement structure), the progressive sequence is $10.0 \%<6.0 \%<\mathrm{N} 50 / 70<3.0 \%<0 \%<0.5 \%<$ PMBTS. For the applied strain of 5\% (representative strain level of a "strong" pavement structure), the progressive sequence is $10.0 \%<6.0 \%<3.0 \%<\mathrm{N} 50 / 70$ $<0 \%<0.5 \%<$ PMBTS. High contents of nano- $\mathrm{TiO}_{2}$ slightly reduced the binder fatigue resistance. Additionally, higher differences are found for an applied strain level of $5 \%$, related to the strong pavement structures.

\subsection{Rutting Resistance Indicator (MSCR Test)}

The MSCR test was introduced as a test to evaluate the resistance to permanent deformation (rutting) as well as a tool to evaluate the quality of polymer modified binders [40,41]. Generally, a combination of high recovery $(R)$ and low non-recoverable compliance $(J n r)$ indicates a good quality PMB that can be used in high traffic pavements, as described in AASHTO M332. Such limits that distinguish between the acceptance levels for different traffic levels have not been established by the 
EN 16659. Therefore, a comparative evaluation of the rutting resistance of the binders in this study is presented.

The MSCR test results are presented in Table 2. Considering the $\% R$, the transparent binders exhibit a recovery between the reference binders (higher than N50/70 but lower than PMBTS), but with values closer to PMBTS. At a stress level of $100 \mathrm{~Pa}$, while the conventional binder N50/70 demonstrates recovery of only $9.0 \%$, the transparent binders show at least $63.6 \%$ and the PMBTS $82.1 \%$.

Table 2. MSCR test results.

\begin{tabular}{ccccc}
\hline \multirow{2}{*}{ Binder } & \multicolumn{4}{c}{ Parameter } \\
\cline { 2 - 5 } & $\boldsymbol{J n} \boldsymbol{r}, \mathbf{1 0 0}\left(\mathbf{k P a}^{-\mathbf{1}}\right)$ & $\boldsymbol{J n} \boldsymbol{r}, \mathbf{3 2 0 0} \mathbf{( \mathbf { k P a } ^ { - \mathbf { 1 } } )}$ & $\mathbf{R 1 0 0} \mathbf{( \% )}$ & $\mathbf{R 3 2 0 0}(\mathbf{\%})$ \\
\hline $0 \%$ & 0.2 & 0.2 & 64.8 & 63.2 \\
$0.5 \%$ & 0.2 & 0.2 & 63.6 & 62.3 \\
$3.0 \%$ & 0.2 & 0.2 & 65.5 & 63.8 \\
$6.0 \%$ & 0.1 & 0.1 & 69.9 & 64.4 \\
$10.0 \%$ & 0.1 & 0.1 & 73.1 & 65.8 \\
N50/70 & 0.6 & 0.6 & 9.0 & 6.0 \\
PMBTS & 0.0 & 0.0 & 82.1 & 85.7 \\
Kromatis 50/70 & 1.8 & 2.3 & 27.6 & 16.6 \\
from [3] & & & & \\
\hline
\end{tabular}

The incorporation of nano- $\mathrm{TiO}_{2}$ increased the $\mathrm{R} 100$ for the contents $6.0 \%$ and $10.0 \%$ when compared to $0 \%$. The contents $0.5 \%$ and $3.0 \%$ had similar R100 to $0 \%$. For R3200, the transparent binders had similar results, from $63.2 \%$ to $65.8 \%$, for $0 \%$ and $10.0 \% \mathrm{TiO}_{2}$ addition respectively.

Regarding the $J n r$ values, again, the transparent binders show an intermediate behavior between the reference binders N50/70 and PMBTS. The incorporation of nano- $\mathrm{TiO}_{2}$ decreased the $\mathrm{Jnr}(100$ and $3200 \mathrm{~Pa}^{-1}$ ) for the contents $3.0 \%, 6.0 \%$ and $10.0 \%$ when compared to $0 \%$. As can be expected, the content $0.5 \%$ had a similar $J n r$ to $0 \%$ (transparent base binder).

Sengoz et al. (2017) analyzed the same Kromatis 50/70 from the same supplier. They indicated values of R\% between the N50/70 and PMBTS as well, 27.6\% and 16.6\% for $100 \mathrm{~Pa}$ and $3200 \mathrm{~Pa}$, respectively [3]. Nevertheless, their results are closer to the N50/70 than the PMBTS. Considering Jnr, the results from Sengoz et al. (2017) are much higher than those obtained in this research for all the binders (base, modified, and reference ones).

It can be concluded that the transparent binders present better rutting resistance than the conventional N50/70 with higher recovery and lower non-recoverable creep compliance. This fact was expected, since the transparent binder contains elastomeric polymers, as demonstrated earlier in Section 4.3. However, the transparent binders presented lower rutting resistance than the PMBTS. The incorporation of nano- $\mathrm{TiO}_{2}$ can increase the rutting resistance for high contents (mainly $6.0 \%$ and $10.0 \%)$.

\subsection{FTIR}

\subsubsection{Peak Identification}

The FTIR spectra (absorbance versus wavelength) of the $\left(\mathrm{TiO}_{2}\right.$-modified) transparent binders, the reference binders, and the pure $\mathrm{TiO}_{2}$ are shown in Figure 8. Peaks at $2953 \mathrm{~cm}^{-1}$ and $2862 \mathrm{~cm}^{-1}$ are associated with stretching vibrations of $s p^{3} \mathrm{C}-\mathrm{H}$ in aliphatic chains, as asymmetric and symmetric stretches, respectively. Peaks at $1460 \mathrm{~cm}^{-1}$ are characteristic of bending vibrations of methylene groups $\left(-\left(\mathrm{CH}_{2}\right)_{\mathrm{n}}\right)$. The peak at $1375 \mathrm{~cm}^{-1}$ is attributed to the bending of methyl groups $\left(-\mathrm{CH}_{3}\right)$, which is related to aliphatic branched bands. The long-chain band can be seen at $724 \mathrm{~cm}^{-1}$, associated with the rocking motion of $-\mathrm{CH}_{2}$ groups in an aliphatic chain. The peak at $1700 \mathrm{~cm}^{-1}$ is related to the stretching of carbonyl band $\mathrm{C}=\mathrm{O}$ typical of carboxylic acids [42], being one of the most important peaks for the asphalt binder aging [43-45]. 


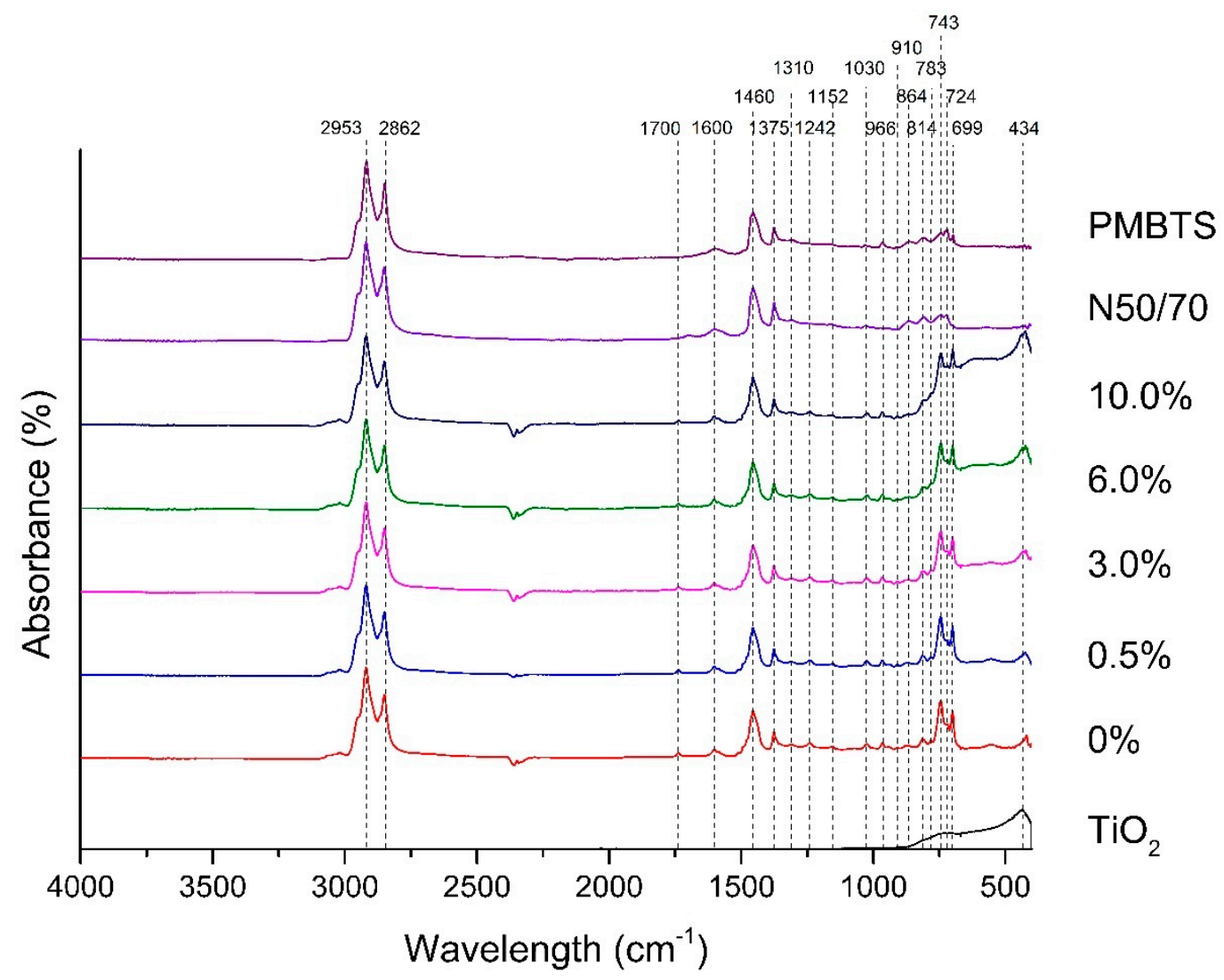

Figure 8. FTIR spectra of the binders of this study.

Stretching absorptions of $\mathrm{C}=\mathrm{C}$ bond in aromatic rings occur at the peaks at $1600 \mathrm{~cm}^{-1}$. The peaks that appear between $910 \mathrm{~cm}^{-1}$ and $699 \mathrm{~cm}^{-1}$ can be analyzed carefully to show ortho-, meta- and para-disubstituted rings presented in aromatic compounds and are associated with out-of-plane $\mathrm{C}-\mathrm{H}$ bending vibrations in this structure. Due to the complex composition of the asphalt binders, all these compounds may be presented in the analyzed samples. For example, the pair $743 \mathrm{~cm}^{-1}$ and $699 \mathrm{~cm}^{-1}$ can match with monosubstituted rings; a single peak at $743 \mathrm{~cm}^{-1}$ may be associated with 1,2-disubstituted rings; peaks at $864 \mathrm{~cm}^{-1}, 783 \mathrm{~cm}^{-1}$, and $699 \mathrm{~cm}^{-1}$ may be attributed to 1,3-disubstituted rings; and finally, the pair $864 \mathrm{~cm}^{-1}$ and $814 \mathrm{~cm}^{-1}$ can match to 1,4-disubstituted rings [43-45].

The peaks at $966 \mathrm{~cm}^{-1}$ and $699 \mathrm{~cm}^{-1}$ may still correspond to the bending out-of-plane of C-H of trans-alkenes (from polybutadiene) and $\mathrm{C}-\mathrm{H}$ out-of-plane bending in monoalkylated aromatics (from polystyrene) associated with SBS. The peak at $910 \mathrm{~cm}^{-1}$ can also show terminal-alkenes [43]. The peak at $1375 \mathrm{~cm}^{-1}$ may be associated with the asymmetric stretch of sulfonyl chlorides $\mathrm{S}=\mathrm{O}$ bond. While the peaks at $1310 \mathrm{~cm}^{-1}$ and $1152 \mathrm{~cm}^{-1}$ are typical of respectively asymmetric and symmetric stretches of sulfones $\mathrm{S}=\mathrm{O}$ bonds [13]. At $1030 \mathrm{~cm}^{-1}$, there is the other peak directly related to asphalt binder aging, the stretch of sulfoxide $\mathrm{S}=\mathrm{O}$ bond [43-45]. The peak $1242 \mathrm{~cm}^{-1}$ can be linked to the asymmetric stretching vibration of sulfate esters [13].

For the transparent binders, the peak $434 \mathrm{~cm}^{-1}$ represents a stretching vibration of metal oxides (M-O) bond ( $\mathrm{M}$ can be $\mathrm{Si}, \mathrm{Mn}, \mathrm{V}, \mathrm{Ni}$, and others) [46-49]. This peak $\left(434 \mathrm{~cm}^{-1}\right)$ is also attributed to stretch absorptions of $\mathrm{Ti}-\mathrm{O}$ bond [50], and the increase in this peak area in the $\mathrm{TiO}_{2}-$ modified transparent binders may indicate the proper incorporation of the semiconductor in the asphalt binder.

\subsubsection{Relationship between the $\mathrm{TiO}_{2}$ Modification Level and the Chemical Responsible}

Figure 9 shows the graph $R I$ versus $\% \mathrm{TiO}_{2}$. It can also be seen that the addition of nano- $\mathrm{TiO}_{2}$ increases the relative increase $R I$ (from $\mathrm{TiO}_{2}$ related vibration area). A linear correlation of the nano- $\mathrm{TiO}_{2}$ percentage and the RI can be found. To some extent, this shift of the spectra with the addition of 
nano- $\mathrm{TiO}_{2}$ is to be expected, as the vibrations become more evident when the binder is more diluted. The high correlation coefficient $\left(\mathrm{R}^{2}=0.99\right)$ of the increase of this index with the modification level (Figure 9) confirms the assumption that nano- $\mathrm{TiO}_{2}$ can be used as a marker in bituminous blends [51,52]. This analysis can be used in order to assess the presence of $\mathrm{TiO}_{2}$ and quantify its incorporation as a binder modifier.

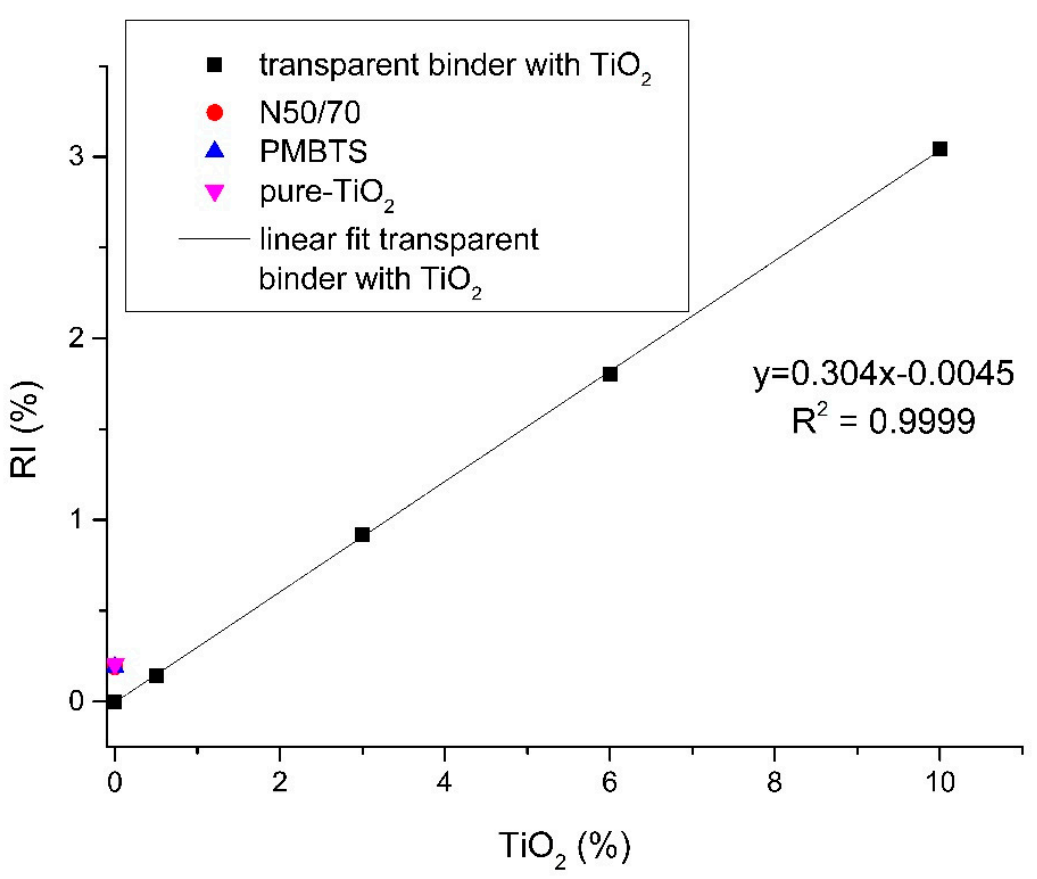

Figure 9. Correlation of the nano- $\mathrm{TiO}_{2}$ modification level with the increase of the $\mathrm{TiO}_{2}$-related index.

4.6.3. Relationship between the $\mathrm{TiO}_{2}$ Modification Level and the Chemical Responsible

The results of FTIR are presented in Figure 10 in terms of oxygen- and polymer-related indices. The chemical indices sulfoxide, carbonyl, polybutadiene, polystyrene, aromatic, aliphatic, branched aliphatic, and long chains are presented in terms of their normalized intensity. This study confirms that the initial sulfoxide and carbonyl levels of nano- $-\mathrm{TiO}_{2}$-modified are similar to the reference unmodified binder N50/70 and the SBS-modified PMBTS. This observation gives rise to the assumption that the presence of nano- $\mathrm{TiO}_{2}$ does not introduce new functionalities in sulfoxide- or carbonyl-related groups such as esters, carboxylic acids, and ketones. Furthermore, the modification of the binder with nano- $\mathrm{TiO}_{2}$, according to other studies [53,54], can reduce the long-term oxidation performance due to its capability to reflect and absorb UltraViolet (UV) light during photocatalysis. It is also initially chemically neutral for the polar carbonyl groups.

A detailed observation of the two aging-related indices implies that, although of similar magnitude, slightly higher indices can be found compared to the two reference binders N50/70 and PMBTS. This fact can be explained to be the result of the different initial sulfur content for the sulfoxide index. In other words, the origin of the crude oils of the binders is different, and this has a clear implication for the $\mathrm{S}=\mathrm{O}$-containing groups. When examining the slightly higher carbonyl index of the nano-TiO $\mathrm{O}_{2}-\mathrm{modified}$ binders, one can highlight two important points. Firstly, the binder used for modification with nano- $\mathrm{TiO}_{2}$ was different from the unmodified reference binder, and transparent binders show a carbonyl index of the same magnitude. The level of modification seems to have a negligible effect on the initial carbonyl index. That is, the increased carbonyl level can be attributed to the binder used as the base for modification and not the nano- $\mathrm{TiO}_{2}$ addition itself. Following the explanation provided for the higher carbonyl increase of nano- $\mathrm{TiO}_{2}$-modified binders, the same line of thought can be followed for the slightly lower aromatic, branched aliphatic, and long chains indices and the higher aliphatic index compared to the reference binders. 


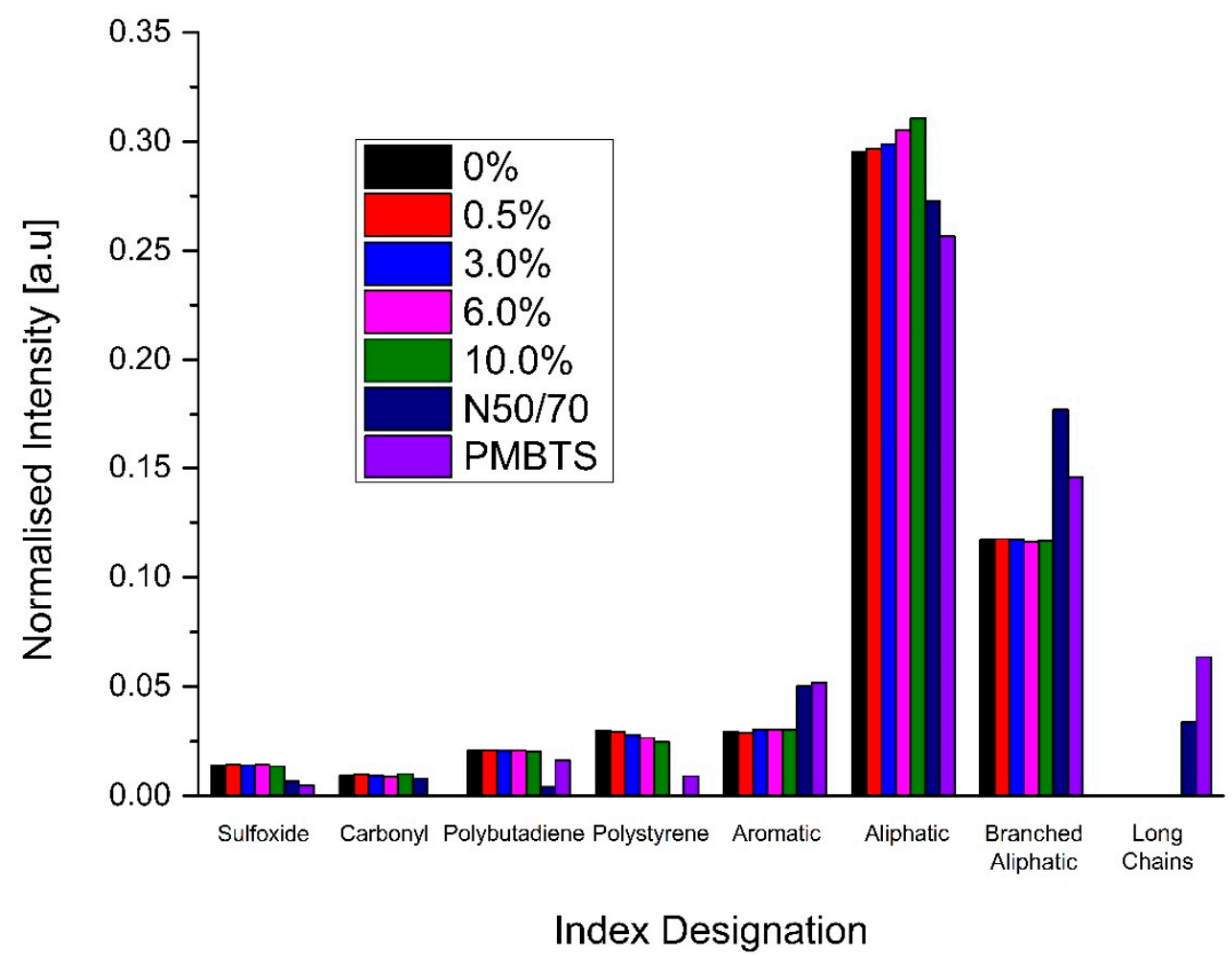

Figure 10. FTIR indices of the nano- $\mathrm{TiO}_{2}$-modified, base and reference binders.

In parallel, as the introduction of elastomeric polymers produces the binder selected as the base for $\mathrm{TiO}_{2}$ modification, the polymer-related indices were evaluated. A comparison of the polybutadiene and polystyrene indices reveals that the binder used for modification (transparent base binder) is highly modified compared to the SBS modified reference binder PMBTS. For the binder N50/70, these indices are not applicable.

In contrast to the rheological parameters, the transparent binders did not show intermediate behavior between the reference binders N50/70 and PMBTS. They showed higher indices for sulfoxides, carbonyl, polybutadiene, polystyrene, and aliphatic but lower for aromatic, branched aliphatic and long chains. Their long chains were null. Moreover, the $\mathrm{TiO}_{2}$ modification seems to have little effect on the indices, except for the polystyrene and aliphatic indices. The polystyrene index decreases, and the aliphatic index increases with the increase of nano- $\mathrm{TiO}_{2}$.

\section{Conclusions}

A transparent binder modified with nano- $\mathrm{TiO}_{2}$ was characterized with respect to its physicochemical and rheological properties in this paper. This is useful for specific applications, such as tunnels, calming traffic areas, among others, as the nano- $\mathrm{TiO}_{2}$ provides to the pavement a photocatalytic function and better visibility. Modified transparent binders, with $0.5 \%, 3.0 \%, 6.0 \%$, and $10.0 \%$ of nano- $\mathrm{TiO}_{2}$, were compared to the transparent base binder and two commercial asphalt binders (conventional and PMB).

Based on the results, the transparent binders (base and modified) performed similarly to the conventional binder and $\mathrm{PMB}$, being workable in terms of their viscosity. The transparent binders clearly revealed the presence of an elastomeric modification, indicating polymer modification, and suggested an alternation of elastic/viscous behavior between the materials that compose the transparent binders.

The incorporation of nano- $\mathrm{TiO}_{2}$ gradually increased the softening point and decreased the penetration by up to $6.0 \%$ of modification, causing no substantial changes in the Complex Modulus of the transparent binder. There is no evidence that the addition of $\mathrm{TiO}_{2}$ up to $10.0 \%$ significantly affects the structure or visco-elastic behavior of the chemical indices, except for the polystyrene and 
aliphatic indices, of either of the transparent binders. Additionally, the addition of $\mathrm{TiO}_{2}$ would reduce the fatigue life of asphalt pavements using the transparent binder. On the contrary, it would increase the rutting resistance for high contents.

Transparent binders with $\mathrm{TiO}_{2}$ give promising results, based on their conventional, rheological, and chemical performance. On the one hand, the best percentage for the addition of $\mathrm{TiO}_{2}$, based on the results, without compromising the performance of the transparent binder, was $0.5 \%$ with respect to fatigue resistance. On the other hand, $10.0 \%$ nano- $\mathrm{TiO}_{2}$ was the best with respect to permanent deformation.

Although the objectives of this research were achieved, it is essential to carry out this analysis on more samples, as limited numbers were used. The next steps of this research are to evaluate the light-colored and photocatalytic pavements considering the properties of color and photocatalysis and analyze the aging performance of the transparent binders with nano- $\mathrm{TiO}_{2}$. Another topic that must be assessed is the analysis of the total life cycle cost (including environmental impact/benefits).

Author Contributions: Conceptualization, I.R.S., E.F., and C.V.; methodology, I.R.S., S.L.J., E.F., and C.V.; validation, J.B., T.T., S.D., and J.C.; formal analysis, I.R.S., S.L.J., A.M., and G.P.; investigation, I.R.S., E.F., C.V., T.T., S.D., and J.C.; resources, E.F., C.V., J.B., T.T., S.D., and J.C.; data curation, I.R.S., S.L.J., A.M., and G.P.; writing-original draft preparation, I.R.S., A.M., and G.P.; writing-review and editing, S.L.J., E.F., C.V., J.B., T.T., S.D., and J.C.; visualization, I.R.S, E.F., and C.V.; supervision, E.F., C.V., and J.C.; project administration, E.F., C.V., J.C.; funding acquisition, E.F., C.V., J.B., T.T., S.D., and J.C. All authors have read and agreed to the published version of the manuscript.

Funding: FCT partially financed this work-Fundação para a Ciência e a Tecnologia-under the projects for Strategic Funding UIDB/04650/2020 and UIDB/04029/2020, and Nanobased concepts for Innovative and Eco-sustainable constructive material surfaces PTDC/FIS/120412/2010. Furthermore, we would like to thank the Industrial Research Fund (IOF) of the University of Antwerp for funding the PAPPoA project (IOF/SBO/41859/2020). Lastly, the first author would like to acknowledge FCT for the PhD scholarship (SFRH/BD/137421/2018).

Conflicts of Interest: The authors declare no conflict of interest.

\section{References}

1. Bocci, M.; Grilli, A.; Cardone, F.; Virgili, A. Clear Asphalt Mixture for Wearing Course in Tunnels: Experimental Application in the Province of Bolzano. In Proceedings of the SIIV—5th International Congress-Sustainability of Road Infrastructures, Rome, Italy, 29-31 October 2012; Elsevier B.V.: Rome, Italy, 2012; Volume 53, pp. 115-124.

2. Chen, Z.; Zhang, H.; Zhu, C.; Zhao, B. Rheological examination of aging in bitumen with inorganic nanoparticles and organic expanded vermiculite. Constr. Build. Mater. 2015, 101, 884-891. [CrossRef]

3. Sengoz, B.; Bagayogo, L.; Oner, J.; Topal, A. Investigation of rheological properties of transparent bitumen. Constr. Build. Mater. 2017, 154, 1105-1111. [CrossRef]

4. Guan, B. Application of asphalt pavement with phase change materials to mitigate urban heat island effect. In Proceedings of the 2011 International Symposium on Water Resource and Environmental Protection, Xi'an, China, 20-22 May 2011; pp. 2389-2392.

5. Yu, H.; Dai, W.; Qian, G.; Gong, X.; Zhou, D.; Li, X.; Zhou, X. The NOx Degradation Performance of Nano- $\mathrm{TiO}_{2}$ Coating for Asphalt Pavement. Nanomaterials 2020, 10, 897. [CrossRef] [PubMed]

6. Rocha Segundo, I.; Freitas, E.; Landi, S., Jr.; Costa, M.F.M.; Carneiro, J.O. Smart, Photocatalytic and Self-Cleaning Asphalt Mixtures: A Literature Review. Coatings 2019, 9, 696. [CrossRef]

7. Carneiro, J.O.O.; Azevedo, S.; Teixeira, V.; Fernandes, F.; Freitas, E.; Silva, H.; Oliveira, J. Development of photocatalytic asphalt mixtures by the deposition and volumetric incorporation of $\mathrm{TiO}_{2}$ nanoparticles. Constr. Build. Mater. 2013, 38, 594-601. [CrossRef]

8. Rocha Segundo, I.; Ferreira, C.; Freitas, E.F.; Carneiro, J.O.; Fernandes, F.; Landi Júnior, S.; Costa, M.F. Assessment of photocatalytic, superhydrophobic and self-cleaning properties on hot mix asphalts coated with $\mathrm{TiO}_{2}$ and/or $\mathrm{ZnO}$ aqueous solutions. Constr. Build. Mater. 2018, 166, 36-44. [CrossRef]

9. Hassan, M.M.; Dylla, H.; Mohammad, L.N.; Rupnow, T. Evaluation of the durability of titanium dioxide photocatalyst coating for concrete pavement. Constr. Build. Mater. 2010, 24, 1456-1461. [CrossRef] 
10. Rocha Segundo, I.G.; Dias, E.A.L.; Fernandes, F.D.P.; Freitas, E.F.; Costa, M.F.; Carneiro, J.O. Photocatalytic asphalt pavement: The physicochemical and rheological impact of $\mathrm{TiO}_{2}$ nano/microparticles and $\mathrm{ZnO}$ microparticles onto the bitumen. Road Mater. Pavement Des. 2018. [CrossRef]

11. Rocha Segundo, I.; Landi, S., Jr.; Oliveira, S.; Freitas, E.; Costa, M.F.; Carneiro, J. Photocatalytic asphalt mixtures: Semiconductors' impact in skid resistance and texture. Road Mater. Pavement Des. 2019. [CrossRef]

12. Carnielo, E.; Zinzi, M. Optical and thermal characterisation of cool asphalts to mitigate urban temperatures and building cooling demand. Build. Environ. 2013, 60, 56-65. [CrossRef]

13. Mirwald, J.; Werkovits, S.; Camargo, I.; Maschauer, D.; Hofko, B.; Grothe, H. Understanding bitumen ageing by investigation of its polarity fractions. Constr. Build. Mater. 2020, 250, 118809. [CrossRef]

14. Bocci, E.; Bocci, M. Clear asphalt concrete for energy saving in road tunnels Clear asphalt concrete for energy saving in road tunnels. In Proceedings of the 12th International Society for Asphalt Pavements, Raleigh, North Carolina, 1-5 June 2014.

15. Bocci, M. Projekt INTERREG IV Innovative Beläge und Beleuchtung für Tunnel iBBT (ID 5273); Marche Polytechnic University: Ancona, Italy, 2012.

16. Nejad, F.M.; Tanzadeh, R.; Tanzadeh, J.; Hamedi, G.H. Investigating the effect of nanoparticles on the rutting behaviour of hot-mix asphalt. Int. J. Pavement Eng. 2016, 17, 353-362. [CrossRef]

17. Sun, L.; Xin, X.; Ren, J. Asphalt modification using nano-materials and polymers composite considering high and low temperature performance. Constr. Build. Mater. 2017, 133, 358-366. [CrossRef]

18. Shafabakhsh, G.H.; Ani, O.J. Experimental investigation of effect of $\mathrm{Nano} \mathrm{TiO}_{2} / \mathrm{SiO}_{2}$ modified bitumen on the rutting and fatigue performance of asphalt mixtures containing steel slag aggregates. Constr. Build. Mater. 2015, 98, 692-702. [CrossRef]

19. Khan, M.I.; Sutanto, M.H.; Sunarjono, S.; Room, S. Effect of Crumb Rubber, Epolene (EE-2), and Date Palm Ash as Modifiers on the Performance of Binders and Mixtures: A Sustainable Approach. Sustainability 2019, 11, 6484. [CrossRef]

20. FHA. Superpave Fundamentals Reference Manual; FHA, U.S. Department of Transportation: Washington, DC, USA, 2005.

21. RHEA. Rheology Analysis Software, Version 1.2. 1; Abatech. Inc.: Bloom Glen, PA, USA, 2011.

22. Gordon, G.V.; Shaw, M.T. Computer Programs für Rheologists; Hanser: Munich, Germany, 1994; ISBN 3446162909.

23. Airey, G.D. Use of Black Diagrams to Identify Inconsistencies in Rheological Data. Road Mater. Pavement Des. 2002, 3, 37-41. [CrossRef]

24. Hintz, C.; Velasquez, R.; Johnson, C.; Bahia, H. Modification and Validation of Linear Amplitude Sweep Test for Binder Fatigue Specification. Transp. Res. Rec. J. Transp. Res. Board 2011, 2207, 99-106. [CrossRef]

25. Masad, E.; Somadevan, N.; Bahia, H.U.; Kose, S. Modeling and Experimental Measurements of Strain Distribution in Asphalt Mixes. J. Transp. Eng. 2001, 127, 477-485. [CrossRef]

26. Kleiziene, R.; Panasenkienè, M.; Vaitkus, A. Effect of Aging on Chemical Composition and Rheological Properties of Neat and Modified Bitumen. Materials 2019, 12, 4066. [CrossRef]

27. Feng, L.Z.; Bian, H.; Li, X.; Yu, J. FTIR analysis of UV aging on bitumen and its fractions. Mater. Struct. 2016, 49, 1381-1389. [CrossRef]

28. Yut, I.; Zofka, A. Attenuated Total Reflection (ATR) Fourier Transform Infrared (FT-IR) Spectroscopy of Oxidized Polymer-Modified Bitumens. Appl. Spectrosc. 2011, 65, 765-770. [CrossRef] [PubMed]

29. Marsac, P.; Piérard, N.; Porot, L.; Van den bergh, W.; Grenfell, J.; Mouillet, V.; Pouget, S.; Besamusca, J.; Farcas, F.; Gabet, T.; et al. Potential and limits of FTIR methods for reclaimed asphalt characterisation. Mater. Struct. 2014. [CrossRef]

30. Dony, A.; Ziyani, L.; Drouadaine, I.; Pouget, S.; Faucon-Dumont, S.; Simard, D.; Mouillet, V.; Poirier, J.E.; Gabet, T.; Boulange, L.; et al. MURE National Project: FTIR spectroscopy study to assess ageing of asphalt mixtures. In Proceedings of the E\&E Congress, Prague, Czech Republic, 1-3 June 2016.

31. Zhang, Z.; Kang, N.; Zhou, J.; Li, X.; He, L. Novel Synthesis of Choline-Based Amino Acid Ionic Liquids and Their Applications for Separating Asphalt from Carbonate Rocks. Nanomaterials 2019, 9, 504. [CrossRef] [PubMed]

32. Lamontagne, J.; Dumas, P.; Mouillet, V.; Kister, J. Comparison by Fourier transform infrared (FTIR) spectroscopy of different ageing techniques: Application to road bitumens. Fuel 2001, 80, 483-488. [CrossRef] 
33. Rajakumar, G.; Rahuman, A.A.; Roopan, S.M.; Khanna, V.G.; Elango, G.; Kamaraj, C.; Zahir, A.A.; Velayutham, K. Molecular and Biomolecular Spectroscopy Fungus-mediated biosynthesis and characterization of $\mathrm{TiO}_{2}$ nanoparticles and their activity against pathogenic bacteria. Spectrochim. Acta Part A 2012, 91, 23-29. [CrossRef]

34. Jaimy, K.B.; Ghosh, S.; Sankar, S.; Warrier, K.G.K. An aqueous sol—gel synthesis of chromium (III) doped mesoporous titanium dioxide for visible light photocatalysis. Mater. Res. Bull. 2011, 46, 914-921. [CrossRef]

35. Wei, J.; Zhao, L.; Peng, S.; Shi, J.; Liu, Z.; Wen, W. Wettability of urea-doped $\mathrm{TiO}_{2}$ nanoparticles and their high electrorheological effects. J. Sol-Gel Sci. Technol. 2008, 311-315. [CrossRef]

36. Homem, N.C.; de Beluci, N.C.; Amorim, S.; Reis, R.; Vieira, A.M.; Vieira, M.F.; Bergamasco, R.; Amorim, M.T.P. Applied Surface Science Surface modification of a polyethersulfone micro fi ltration membrane with graphene oxide for reactive dyes removal. Appl. Surf. Sci. 2019, 486, 499-507. [CrossRef]

37. Kataware, A.V.; Singh, D. Dynamic mechanical analysis of crumb rubber modified asphalt binder containing warm mix additives. Int. J. Pavement Eng. 2017, 8436. [CrossRef]

38. Airey, G.D. Rheological properties of styrene butadiene styrene polymer modified road bitumens. Fuel 2003, 82, 1709-1719. [CrossRef]

39. Soenen, H.; De Visscher, J.; Vanelstraete, A.; Redelius, P. Influence of thermal history on rheological properties of various bitumen. Rheol. Acta 2006, 45, 729-739. [CrossRef]

40. Hossain, Z.; Ghosh, D. Use of the Multiple Stress Creep Recovery ( MSCR ) Test Method to Characterize Polymer-Modified Asphalt Binders. J. Test. Eval. 2016, 44. [CrossRef]

41. Ren, Z.; Zhu, Y.; Wu, Q.; Zhu, M.; Guo, F.; Yu, H. Enhanced Storage Stability of Different Polymer Modified Asphalt Binders through Nano-Montmorillonite Modification. Nanomaterials 2020, 10, 641. [CrossRef]

42. Homem, N.C.; Yamaguchi, N.U.; Vieira, M.F.; Amorim, M.T.S.P.; Bergamasco, R. Surface modification of microfiltration membrane with GO nanosheets for dyes removal from aqueous solutions. Chem. Eng. Trans. 2017, 60, 259-264.

43. Masson, J.F.; Pelletier, L.; Collins, P. Rapid FTIR method for quantification of styrene-butadiene type copolymers in bitumen. J. Appl. Polym. Sci. 2001, 79, 1034-1041. [CrossRef]

44. Zhang, H.; Su, M.; Zhao, S.; Zhang, Y.; Zhang, Z. High and low temperature properties of nano-particles/ polymer modified asphalt. Constr. Build. Mater. 2016, 114, 323-332. [CrossRef]

45. Yao, H.; You, Z.; Li, L.; Lee, C.H.; Wingard, D.; Yap, Y.K.; Shi, X.; Goh, S.W. Rheological Properties and Chemical Bonding of Asphalt Modified with Nanosilica. J. Mater. Civ. Eng. 2013, 1619-1630. [CrossRef]

46. Zhao, X.; Wei, L.; Cheng, S.; Huang, Y.; Yu, Y.; Julson, J. Catalytic cracking of camelina oil for hydrocarbon biofuel over ZSM-5-Zn catalyst. Fuel Process. Technol. 2015, 139, 117-126. [CrossRef]

47. Cheng, S.; Wei, L.; Zhao, X.; Kadis, E.; Julson, J. Conversion of Prairie Cordgrass to Hydrocarbon Biofuel over Co-Mo/HZSM-5 Using a Two-Stage Reactor System. Energy Technol. 2016, 4, 706-713. [CrossRef]

48. Zajíčková, L.; Buršíková, V.; Kučerová, Z.; Franclová, J.; St'ahel, P.; Peřina, V.; Macková, A. Organosilicon thin films deposited by plasma enhanced CVD: Thermal changes of chemical structure and mechanical properties. J. Phys. Chem. Solids 2007, 68, 1255-1259. [CrossRef]

49. Urda, A.; Popescu, I.; Marcu, I.C.; Carja, G.; Apostolescu, N.; Sandulescu, I. Methane and propane total oxidation on catalysts from FeLDH precursors. Rev. Chim. 2010, 61, 267-271.

50. Yaseen, M.; Shah, Z.; Veses, R.C.; Dias, S.L.P.; Lima, E.C.; dos Reis, G.S.; Vaghetti, J.C.P.; Alencar, W.S.D.; Mehmood, K. Photocatalytic Studies of $\mathrm{TiO}_{2} / \mathrm{SiO}_{2}$ Nanocomposite Xerogels. J. Anal. Bioanal. Tech. 2017, 8, 1000348. [CrossRef]

51. Jiang, Y.; Gu, X.; Zhou, Z.; Ni, F.; Dong, Q. Laboratory Observation and Evaluation of Asphalt Blends of Reclaimed Asphalt Pavement Binder with Virgin Binder using SEM/EDS. Transp. Res. Rec. 2018, 2672, 69-78. [CrossRef]

52. Rinaldini, E.; Schuetz, P.; Partl, M.N.; Tebaldi, G.; Poulikakos, L.D. Investigating the Blending of Reclaimed Asphalt with Virgin Materials using Rheology, Electron Microscopy and Computer Tomography. Compos. Part B 2014. [CrossRef]

53. Sun, S.S.; Wang, Y.M.; Zhang, A.Q. Study on Anti-Ultraviolet Radiation Aging Property of $\mathrm{TiO}_{2} \mathrm{Modified}^{-}$ Asphalt. Adv. Mater. Res. 2011, 306-307, 951-955. [CrossRef] 
54. Zhang, W.; Shi, J.; Jia, Z. The UV anti-aging performance of TPS modified bitumen. Pet. Sci. Technol. 2018, 36, 1164-1169. [CrossRef]

Publisher's Note: MDPI stays neutral with regard to jurisdictional claims in published maps and institutional affiliations.

(C) 2020 by the authors. Licensee MDPI, Basel, Switzerland. This article is an open access article distributed under the terms and conditions of the Creative Commons Attribution (CC BY) license (http://creativecommons.org/licenses/by/4.0/). 